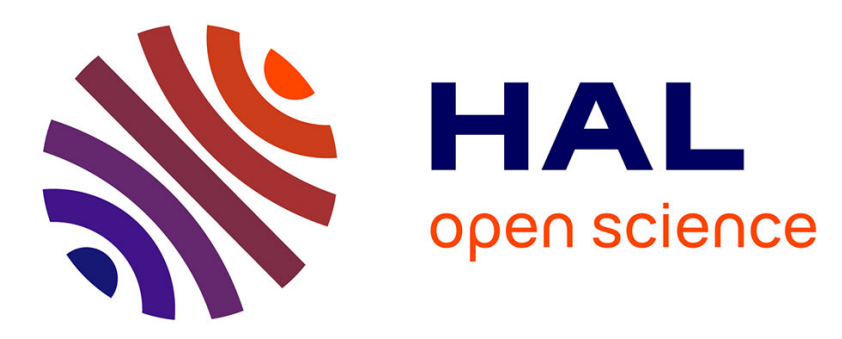

\title{
The residence times of aircraft emissions in the stratosphere using a mean emission inventory and emissions along actual flight tracks
}

Caroline Forster, Andreas Stohl, Paul James, Valérie Thouret

\section{To cite this version:}

Caroline Forster, Andreas Stohl, Paul James, Valérie Thouret. The residence times of aircraft emissions in the stratosphere using a mean emission inventory and emissions along actual flight tracks. Journal of Geophysical Research Space Physics, 2003, 108, pp.8524. 10.1029/2002JD002515 . hal00137521

\section{HAL Id: hal-00137521 \\ https://hal.science/hal-00137521}

Submitted on 23 Aug 2021

HAL is a multi-disciplinary open access archive for the deposit and dissemination of scientific research documents, whether they are published or not. The documents may come from teaching and research institutions in France or abroad, or from public or private research centers.
L'archive ouverte pluridisciplinaire HAL, est destinée au dépôt et à la diffusion de documents scientifiques de niveau recherche, publiés ou non, émanant des établissements d'enseignement et de recherche français ou étrangers, des laboratoires publics ou privés.

\section{(c)(1)}

Distributed under a Creative Commons Attribution| 4.0 International License 


\title{
The residence times of aircraft emissions in the stratosphere using a mean emission inventory and emissions along actual flight tracks
}

\author{
Caroline Forster, Andreas Stohl, and Paul James \\ Lehrstuhl für Bioklimatologie und Immissionsforschung, University of Munich, Freising, Germany \\ Valérie Thouret \\ Laboratoire d'Aérologie, UMR 5560, Centre National de Recherche Scientifique/Université Paul Sabatier, Toulouse, France
}

[1] Flight routes of commercial aircraft are adjusted to the actual meteorological situation in order to benefit from tail winds and avoid head winds and dangerous flight conditions. This study investigates whether these adjustments have an impact on the partitioning and the residence times of aircraft emissions in the stratosphere and troposphere. A Lagrangian dispersion model is used in combination with a mean emission inventory and emissions along actual flight tracks. Both inventories are established from Measurement of Ozone and Water Vapor by Airbus In-Service Aircraft (MOZAIC) aircraft position data in the North Atlantic Flight Corridor (NAFC) over a 1-year period. The results show that stratospheric emissions released in the NAFC are transported in a northeasterly direction towards polar regions on a timescale of a few days. The mean residence time of these emissions is about 23 days, which is shorter than documented in previous studies. The greatest fluxes from the stratosphere into the troposphere occur during the first 10 days and have their maxima over Europe and North Africa. About $62 \%$ and $67 \%$ of the emissions are directly deposited in the stratosphere in the mean emission inventory and in the inventory of the actual flight tracks, respectively. The deposition in the stratosphere was found to be sensitive to the definition of the tropopause height. However, the transport and partitioning of the emissions in the stratosphere and troposphere are only moderately affected if an inventory of the actual flight tracks is used instead of a mean emission inventory. Therefore, the systematic errors made in chemistry climate models, which use mean inventories, are small and can be tolerated for most applications.

\section{Introduction}

[2] Aircraft inject various gases and particles directly into the upper troposphere and lower stratosphere (UTLS). Since the residence times of atmospheric gases are considerably longer there than at the Earth's surface, aircraft emissions have an important impact on atmospheric composition and chemistry in the tropopause region [e.g., Fabian and Kärcher, 1997; Brasseur et al., 1998]. The exhaust triggers the formation of condensation trails, and alters the concentrations of atmospheric greenhouse gases like water vapor $\left(\mathrm{H}_{2} \mathrm{O}\right)$ and ozone $\left(\mathrm{O}_{3}\right)$ in the UTLS, which influence the radiative forcing of the atmosphere. Pollution by aircraft, thus, contributes to climate change [IPCC, 1999; Schumann, 1994].
[3] The production rate of $\mathrm{O}_{3}$ depends critically on the concentration of $\mathrm{NO}_{x}$, where $\mathrm{NO}_{x}=\mathrm{NO}_{2}$ (nitrogen dioxide) $+\mathrm{NO}$ (nitric oxide). Increases in the concentration of $\mathrm{NO}_{x}$ therefore increase the rate of $\mathrm{O}_{3}$ production and can shift the chemical regime from net $\mathrm{O}_{3}$ destruction (below about 20 pptv $\mathrm{NO}_{x}$ ) to net $\mathrm{O}_{3}$ formation [IPCC, 1999]. Furthermore, the number of molecules of $\mathrm{O}_{3}$ produced per molecule of $\mathrm{NO}_{x}$ emitted is significantly higher in the upper troposphere than in the (polluted) boundary layer. Therefore, although the total mass of $\mathrm{NO}_{x}$ emitted by aircraft is relatively small compared to other sources [e.g., Lee et al., 1997; Logan, 1983], aircraft $\mathrm{NO}_{x}$ emissions play an important role for the $\mathrm{O}_{3}$ chemistry in the UTLS.

[4] Since the beginning of the 1990s, the aviation emissions and their impact on the Earth's atmosphere were 
investigated in a sequence of research programs like AERONOX [Schumann, 1995], POLINAT [Schumann, 1997], SONEX [Singh et al., 1999] as part of the NASA Subsonic Assessment Program, NOXAR [Brunner et al., 2001], and others (listed and summarized, for example, in the study of Brasseur et al. [1998]). Numerous studies with global [e.g., Collins et al., 1997; Wauben et al., 1997; Wang et al., 1998] and regional [e.g., Flatøy and Hov, 1996] chemistry climate and transport models estimated present and future $\mathrm{O}_{3}$ impacts from aircraft $\mathrm{NO}_{x}$ emissions on the climate. A bibliography of a number of model studies can be found, for example, in IPCC [1999]. All these model studies predicted significant increases in $\mathrm{NO}_{x}$ and $\mathrm{O}_{3}$ in the tropopause region [IPCC, 1999].

[5] However, the modelling of the effect of aircraft $\mathrm{NO}_{x}$ emissions is restricted by the fact that time-resolved inventories of aircraft emissions are not available. The emission inventories used in chemistry climate models are mean inventories. For instance, the emissions in the ANCAT inventory [Gardner et al., 1997] are estimated from Air Traffic Control data and engine types assuming optimum flight conditions, then averaged over a 3-month period and compiled on a three-dimensional grid. In the NASA inventory [Baughcum et al., 1996] aircraft emissions are available as monthly averages on a three-dimensional grid based on airline schedules and great circle routes. The flight tracks of individual flights, however, are adjusted according to the actual meteorological situation, an effect that mean inventories do not account for. These shifts of the flight tracks might affect significantly the deposition of the emissions into the stratosphere. This is important in terms of atmospheric effects [Anderson, 1973; Hoinka et al., 1993] and might have implications for climate modelling.

[6] In this study we investigate whether there might be significant and systematic errors in the partitioning and residence times of aircraft emissions in the stratosphere, if a mean emission inventory is used instead of the emissions along the actual flight tracks. The paper is organized as follows: section 2 describes the motivation for this study in detail, section 3 describes the modeling tools, the establishment of the emission inventories and the model setup, section 4 presents the results of the model runs, which are discussed in section 5, and the conclusions are drawn in section 6 .

\section{Motivation}

[7] Individual flight tracks are adjusted according to the actual synoptic situation in order to take profit from tail winds and to avoid head winds and dangerous flight conditions. An example for such an adjustment can be seen in Figure 1, where two flight tracks (thick solid lines) between Vancouver and Frankfurt at different times are shown in combination with the height of the geopotential at $200 \mathrm{hPa}$ (gray contour lines). The flight tracks stem from Measurement of Ozone and Water Vapor by Airbus InService Aircraft (MOZAIC) aircraft position data [Marenco et al., 1998]. On 12 November 1999 (Figure 1a), the aircraft takes a route which avoids head winds and profits from the tail winds west and northeast of the low pressure system

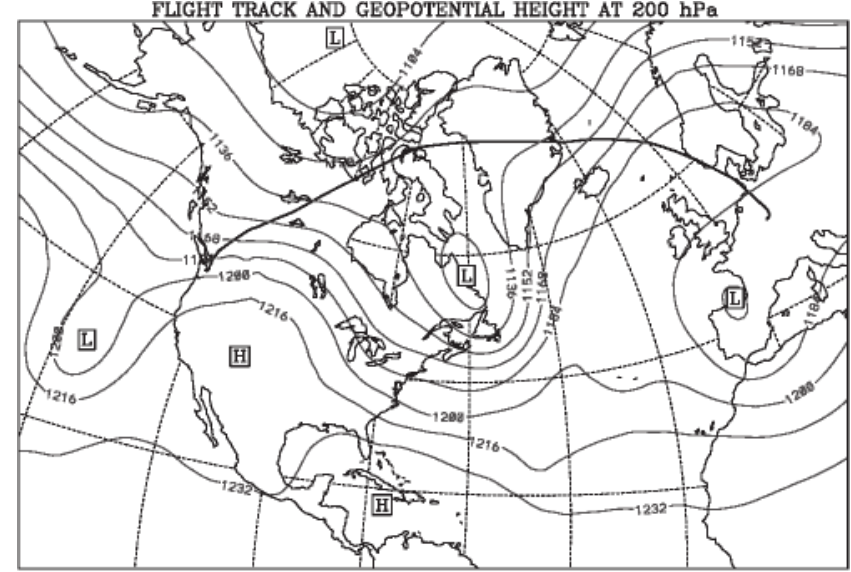

VANCOUVER $->$ FRANKFURT

1999-11-12

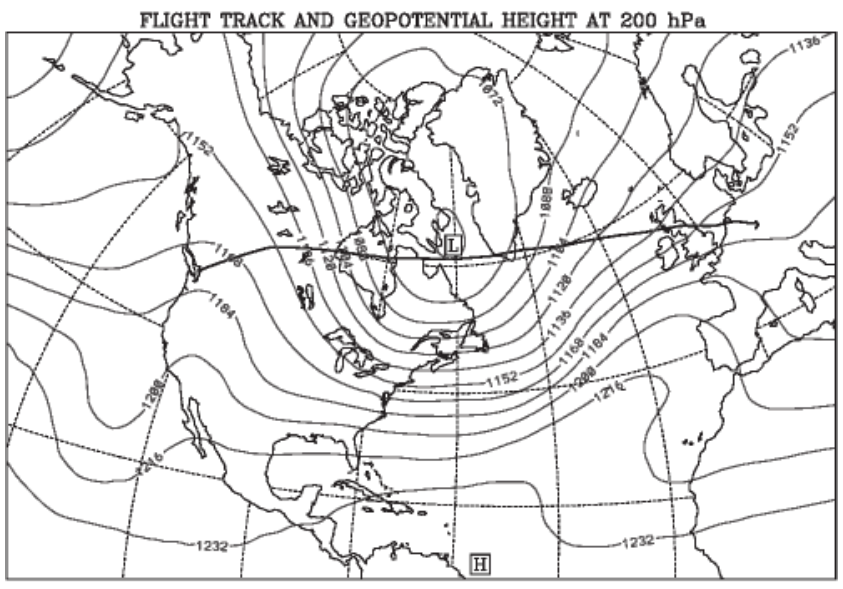

VANCOUVER->FRANKFURT

2000-02-07

Figure 1. Flight tracks (thick solid lines) from Vancouver to Frankfurt (a) on 12 November 1999 and (b) on 7 February 2000. The gray contour lines represent the height of the $200 \mathrm{hPa}$ geopotential in geopotential decameters (gpdm) at 12 UTC on the respective day.

located over east Canada. On 7 February 2000 (Figure 1b), the aircraft again takes a path with strong tail winds. It passes the low-pressure system in the south approximately flying with the jet stream. Although the start and the destination of both flights are the same, the tracks shown in Figure 1 differ substantially from each other, and the figure demonstrates nicely the day-to-day variations in where the aircraft emissions take place. These shifts of the flight routes affect the partitioning of the emissions into the troposphere and the stratosphere. From the method to be explained in section 3 it can be determined that $10 \%$ less emissions are deposited in the stratosphere during the flight on 7 February 2000 (Figure 1b) compared to the flight in Figure 1a. Our basic question is whether this effect is strong enough to cause a systematic error or underestimation of emissions in the stratosphere, if an annually averaged emission inventory is used instead of the actual flight tracks.

[8] We approach the problem by comparing two simulations with a tracer transport model: a simulation using a mean aircraft emission inventory (hereinafter referred to as mean run), and another one using an inventory of emissions 
along the actual flight tracks (hereinafter referred to as actual run).

\section{Modeling Tools, Data, and Model Setup 3.1. The FLEXPART Dispersion Model}

[9] The simulations are carried out with the Lagrangian particle dispersion model FLEXPART [Stohl et al., 1998; Stohl and Thomson, 1999], which calculates the transport and dispersion of nonreactive tracers. FLEXPART is driven by atmospheric observations archived at hybrid model levels at the European Centre for Medium-Range Weather Forecasts (ECMWF) [ECMWF, 1995]. The ECMWF model has been upgraded to 60 model levels in October 1999. In order to have a good vertical resolution for our simulations in both the troposphere and the stratosphere, we have chosen the time period from November 1999 to April 2001 in the present study. These data are global, have a resolution of $1^{\circ}$ longitude $\times 1^{\circ}$ latitude and are available every 3 hours (analyses at 0, 6, 12, and 18 UTC; 3-hour forecasts at 3, 9, 15, and 21 UTC). Advection and turbulent diffusion are treated by calculating the trajectories of a multitude of particles. Transport by turbulent eddies is simulated by solving Langevin equations [Stohl and Thomson, 1999], and the tracer concentrations on a three-dimensional grid are determined by applying a kernel method. In the present study, we simulate the transport of a passive $\mathrm{NO}_{x}$ aircraft tracer without accounting for chemical processes and wet/dry deposition similar to the studies by Schoeberl et al. [1998] and Schoeberl and Morris [2000]. Thus, we consider an idealized $\mathrm{NO}_{x}$ tracer, which does not compare with conventional aircraft $\mathrm{NO}_{x}$ studies [e.g., Brasseur et al., 1996; Wauben et al., 1997]. In addition, only grid-scale convection is accounted for. The particles are randomly redistributed within two or more vertical layers, if the temperature profile between these layers is conditionally unstable. Subgrid-scale deep convection is switched off, as the convection scheme currently implemented in the FLEXPART model needs a lot of computation time. This has only a negligible impact on our results, since we consider aircraft emissions in the midlatitude stratosphere, which are hardly affected by deep convection. A sensitivity study accounting for deep convection has shown that the stratospheric aircraft tracer concentrations differ by only about $2 \%$ from those in a model run without accounting for deep convection.

[10] FLEXPART has been validated with data from three large-scale tracer experiments in North America and Europe [Stohl et al., 1998] and performed well in comparison with other models. It was used to study the intercontinental transport of ozone [Stohl and Trickl, 1999] and the advection of Canadian forest fire emissions to Europe [Forster et al., 2001]. More details on the FLEXPART model can be found in the documentation manual, which can be obtained together with the source code via the Internet from the address http://www.forst.tu-muenchen.de/EXT/LST/ $\mathrm{METEO} / \mathrm{stohl} /$.

\subsection{MOZAIC Data and Emission Inventories}

[11] The emission inventories for the mean and the actual run are established from MOZAIC aircraft position data [Marenco et al., 1998, http://www.aero.obs-mip.fr/mozaic/] covering the period from November 1999 to October 2000.

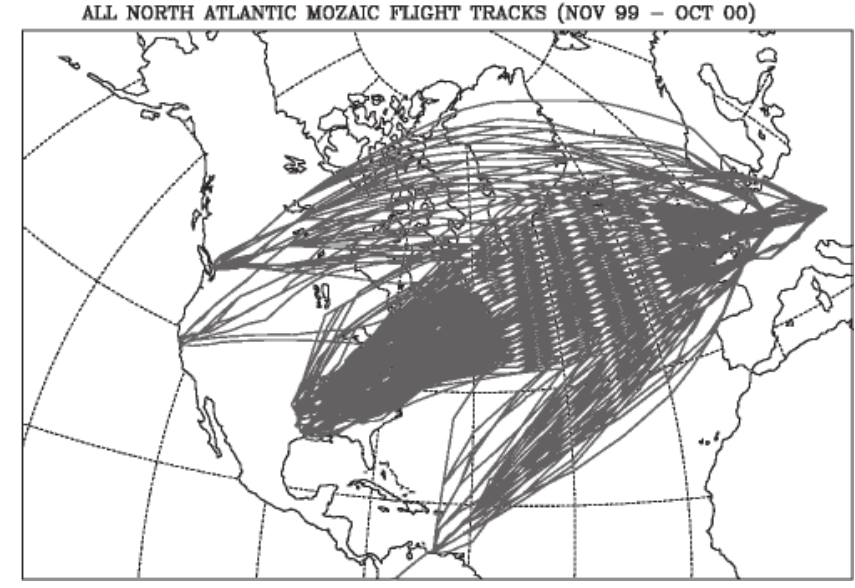

Figure 2. All NAFC MOZAIC flights during the period from November 1999 to October 2000.

The MOZAIC data are available in a time resolution of either $4 \mathrm{~s}$ or about $1 \mathrm{~min}$. In the current study, we used the 1-min resolution data, i.e., at flight level the horizontal distance between two data points is approximately $15 \mathrm{~km}$, which is sufficient for our purpose. The MOZAIC data have been chosen, since the availability of other aircraft position data is limited. For the United States, for example, information about aircraft position data is not available for reasons of national security [Gardner et al., 1997]. We restrict our analysis to the North Atlantic Flight Corridor (NAFC), i.e., between $170^{\circ} \mathrm{W}$ and $30^{\circ} \mathrm{E}$ in the Northern Hemisphere, as most of the MOZAIC flights take place in this region. In addition, the NAFC is a region where local gradients of the tropopause height can be large, such that a slight shift of a flight track might easily be related to a shift from the troposphere (stratosphere) to the stratosphere (troposphere). Therefore, it can be anticipated that great differences between the mean and the actual run occur in the NAFC. Unfortunately, during the period regarded here the MOZAIC data in the NAFC cover only a limited number (1473) of flights for a single aircraft engine type with more flights in winter and spring (750) than in summer and autumn (723).

[12] Figure 2 shows the distribution of all NAFC MOZAIC flights used to establish the emission inventories. Most of the flights take place between $30^{\circ} \mathrm{N}$ and $60^{\circ} \mathrm{N}$. The typical cruising altitude is between 9 and $12 \mathrm{~km}$ above sea level, which corresponds to the tropopause region. Since the location of the tropopause is generally higher in the tropics than in higher latitudes, the flights take place partly in the troposphere and partly in the stratosphere. Depending on the season, about $30-70 \%$ of the NAFC air traffic is flying in the lower stratosphere [Schumann, 1999]. The scattering of the flight tracks shown in Figure 2 again demonstrates that flights are adjusted according to the actual synoptic situation.

[13] The mean run inventory was compiled on a $1^{\circ} \times 1^{\circ}$ grid by $1 \mathrm{~km}$ in altitude. This resolution is comparable to other emission inventories [e.g., Gardner et al., 1997; Baughcum et al., 1996], which were used in climate models. In each grid box the amount of flight kilometers within the 1-year period were counted. An annual mean $\mathrm{NO}_{x}$ emission rate per grid box, was determined by multiplying the flight kilometers in each grid box by a constant $\mathrm{NO}_{x}$ emission rate $R$. Only 
Table 1. List of Age Classes ${ }^{\mathrm{a}}$

\begin{tabular}{cc}
\hline Age Class & Time Period (days) \\
\hline 1 & $0-1$ \\
2 & $1-2$ \\
3 & $2-3$ \\
4 & $3-4$ \\
5 & $4-6$ \\
6 & $6-8$ \\
7 & $8-10$ \\
8 & $10-20$ \\
9 & $20-30$ \\
10 & $30-60$ \\
11 & $60-90$ \\
12 & $90-180$ \\
13 & $0-180$, sum over all age classes \\
\hline
\end{tabular}

${ }^{\mathrm{a}}$ See text for more details.

emissions above $700 \mathrm{hPa}$ are considered, in order to exclude variations of the emissions during takeoff and landing. To our knowledge, no value of $R$ for the Airbus A340, the aircraft type that flew for the MOZAIC project, is given in the literature. Therefore, we assumed $R=92.98 \mathrm{~g} \mathrm{~km}^{-1}$, which is a mean value of annual emission rates of different aircraft types. This number might be somewhat arbitrary, but since we are doing a passive tracer simulation and consider flights for only one aircraft type, our conclusions are not sensitive to the assumed value of $R$.

[14] No regular grid was defined for the actual run inventory. Instead, the distance between two subsequent aircraft positions was counted and multiplied by $R$. The resulting mass is then released in a box, which is located between the two position points and which covers the height difference between the position points in the vertical and $0.2^{\circ} \times 0.2^{\circ}$ in the horizontal. Again only emissions above $700 \mathrm{hPa}$ are accounted for. The release is made over the time the aircraft took to pass the distance between the two position points $(\sim 1 \mathrm{~min})$. Thus, in the actual run the aircraft emissions are released at the actual time the aircraft passed a certain location, whereas in the mean run the same emissions are smeared out over a 1-year period.

\subsection{The Tropopause}

[15] In this study, the tropopause corresponds to the thermal tropopause in tropical regions $\left(20^{\circ} \mathrm{S}\right.$ to $\left.20^{\circ} \mathrm{N}\right)$ and to the dynamical tropopause poleward of $30^{\circ}$, respectively. The thermal tropopause is the lower boundary of a layer with a thickness of $2 \mathrm{~km}$, in which the temperature gradient is lower than $2 \mathrm{~K} \mathrm{~km}^{-1}$ [WMO, 1957; Reiter et al., 1969; Reichler et al., 1996]. The dynamical tropopause is represented by the potential vorticity $(P)$ surface of $P=2$ PVU (1 $\mathrm{PVU}=10^{-6} \mathrm{~km}^{2} \mathrm{~kg}^{-1} \mathrm{~s}^{-3}$ ), a commonly used value for the dynamical tropopause in midlatitudes [e.g., Holton et al., 1995; Appenzeller et al., 1996]. In the region between $\pm 20^{\circ}$ and $\pm 30^{\circ}$ the tropopause is linearly interpolated between the thermal and the dynamical tropopause. In the framework of a sensitivity study, we varied the tropopause between 1 PVU and 4 PVU. This range is larger than that used by, for example, Hoinka [1998] and thus gives an estimate of the maximum influence of the tropopause height definition.

\subsection{Tracer Initialization}

[16] Between November 1999 and October 2000, 4.5 million particles were released in each of the two FLEX-
PART model runs. The number of particles deposited in each release box was determined by dividing its emission rate through the particle mass. In this study, we evaluate only emissions that are released above the tropopause. Each tracer particle emitted there carries a time flag, which corresponds to a clock that counts the residence time in the stratosphere and is stopped as soon as the particle enters the troposphere. It is assumed that once a particle has left the stratosphere, it has adopted tropospheric properties and is regarded as a tropospheric particle even if it is transported back to the stratosphere. The residence times of the particles are split into 13 age classes, which are summarized in Table 1. Note that the release time of the emissions cover the period from November 1999 to October 2000, while the model runs are performed from November 1999 to April 2001 such that it is guaranteed that each particle has gone through each age class.

\section{Results}

[17] In the actual run as well as in the mean run $1.333 \times$ $10^{6} \mathrm{~kg} \mathrm{NO}$ are released in the whole atmosphere, part of which is emitted in the stratosphere. Figure 3 displays the 30 -day running mean of the daily emissions in the stratosphere for the actual (solid curve) and the mean inventory (gray curve) over the period November 1999 to October 2000. For both emission inventories there is a seasonal cycle with more stratospheric emissions taking place in winter than in summer, because on average the tropopause is located at higher altitudes in summer. Compared to the mean inventory, in the actual inventory more emissions are released in the stratosphere during the winter months, but less during the summer months. The variability seen in the

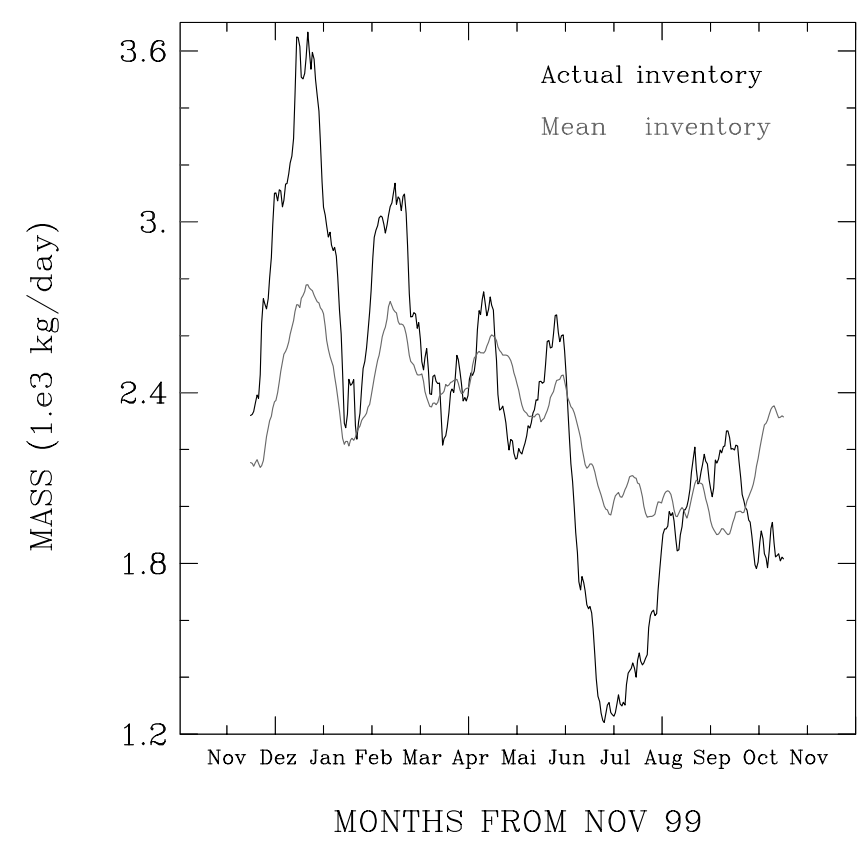

Figure 3. 30-Day running mean of the daily emissions in the stratosphere $\left(\mathrm{kg} \mathrm{d}^{-1}\right)$ from November 1999 to October 2000 for the actual run inventory (solid) and the mean run inventory (gray). 
Table 2. Change in the Fraction of Emissions in the Stratosphere for the Mean Run and Actual Run Inventory as the Tropopause Varies

\begin{tabular}{ccc}
\hline Tropopause & Mean Inventory & Actual Inventory \\
\hline$|\mathrm{P}|=1 \mathrm{PVU}^{\mathrm{a}}$ & 0.68 & 0.69 \\
$|\mathrm{P}|=2 \mathrm{PVU}^{\mathrm{a}}$ & 0.62 & 0.67 \\
$\mathrm{P} \mid=4 \mathrm{PVU}^{\mathrm{a}}$ & 0.48 & 0.52 \\
\hline
\end{tabular}

${ }^{\mathrm{a}}$ In the tropics, appropriate thermal definitions have been defined.

curve of the mean inventory is due to the movement of the tropopause only, as the emissions do not vary from day to day. In contrast, for the actual inventory the variability is due to both the movement of the tropopause and the number of flights, which varies from day to day. The extreme minimum of the stratospheric emissions in the actual inventory in July is due to the fact that during this month fewer flights took place compared to the other months.

[18] In total $62 \%$ and $67 \%$ of the emissions are released in the stratosphere in the mean inventory and in the actual inventory, respectively. The difference is moderate and indicates that the adjustment of the flight tracks to the actual meteorological situation has a relatively small impact on the partitioning of the emissions between the stratosphere and the troposphere. The difference even decreases during the transport, as is shown later.

[19] We evaluated the emissions in the stratosphere relative to different tropopause heights. As additional tropopause heights, we used the 1 PVU and the 4 PVU surface for the dynamical definition in midlatitudes and an appropriate thermal definition in the tropics. Table 2 summarizes the change in fraction of emissions in the stratosphere for the actual and the mean inventory as the tropopause height is varied. Overall, the results in Table 2 are in agreement with other studies [e.g., Baughcum, 1996; Gettelman, 1998; Gettelman and Baughcum, 1999] showing the extent to which the partitioning of the emissions in the stratosphere is sensitive to the height of the tropopause. The difference between the $1 \mathrm{PVU}$ and the 2 PVU tropopause is relatively small compared to the difference between the 2 PVU and the 4 PVU tropopause, because more than a half of the MOZAIC flights take place above the 2 PVU surface [Thouret et al., 2002], whereas in other emissions inventories [e.g., Gardner et al., 1997; Baughcum et al., 1996] aircraft types that fly at lower altitudes than the MOZAIC Airbus A340 are also accounted for. However, the change in fraction of emissions as the tropopause varies is similar in both emission inventories.

[20] The left row of Figure 4 shows the total column of the stratospheric tracer mass for the actual run averaged over the period from November 1999 to April 2001 and split into different age classes. The corresponding stratosphere-to-troposphere fluxes of the stratospheric tracer are displayed in the right row of Figure 4. Within the first day after release, the emissions have not been transported very far. Thus, in age class $1(0-1$ day, Figure $4 a)$ the highest concentrations can be found in the NAFC, with a maximum concentration located over Great Britain and Ireland, the region with the largest number of MOZAIC flights per area. For older tracer ages, e.g., 3-4 days (Figure 4b), the concentration maximum is advected to the northeast and the tracer plume expands in all directions. After 10-20 days (Figure 4c) the emissions are distributed over the entire Northern Hemisphere and the maximum concentrations are found over the polar region. During the first day, transport across the tropopause into the troposphere takes place mainly over the Atlantic and Europe (Figure 4e). After about 3-4 days (Figure 4f) the maximum fluxes are located over Europe and North Africa. At later times, emission fluxes from the stratosphere to the troposphere occur almost everywhere in the Northern Hemisphere (Figure 4g). Maximum cross-tropopause fluxes take place systematically south of the maximum stratospheric tracer columns due to the lower tropopause at higher latitudes. Note that the concentrations decrease continuously with age. Therefore, concentrations of the young age classes dominate those of the older ones, and summing up all age classes reveals maximum concentrations over and north of Great Britain (Figure 4d). Similarly, the fluxes decrease continuously with increasing age of the emissions. Therefore, the fluxes of the younger age classes dominate the fluxes of the older age classes, and most of the emissions are transported to the troposphere over Europe (Figure 4h).

[21] The temporal evolution of the emissions in the stratosphere for the actual run is documented in Figure 5. Most of the emissions are removed from the stratosphere within the first few days. The stratospheric residence time of aircraft emissions is defined as the e-folding time [Rhode, 1992]. It can be computed from $m(t)=m_{0} \exp (-\alpha t)$, where $m(t)$ is the mass of the emissions, $t$ is the time, $m_{0}$ is the initial mass of emissions, and $\alpha^{-1}$ is the e-folding lifetime. An exponential fit to the curve in Figure 5 reveals an efolding lifetime of the emissions of 22 days. The temporal evolution of stratospheric emissions for the mean run (not shown) results in a similar e-folding lifetime of 23 days. Also, the spatial tracer patterns (not shown) are very similar to those of the actual run.

[22] Figure 6 shows the total columns of the stratospheric tracer of the actual minus the mean run averaged over the period November 1999 to April 2001. At the beginning $(0-1$ day, Figure $6 a)$ in the actual run more tracer is located in the northern part of the NAFC and over parts of Europe, but there is also less tracer in the central part of the NAFC. These differences disappear gradually with transport time. After 4-6 days (Figure 6b), the differences are already much less than at the beginning, and for older age classes (not shown) almost no differences remain.

\section{Discussion}

[23] The fractions of total emissions in the stratosphere of $62 \%$ and $67 \%$ that we have found in our study are in good agreement with the values found in a recent study by Thouret et al. [2002]. However, studies of global aircraft emissions report much lower fractions of around $30 \%$ [e.g., Gettelman and Baughcum, 1999]. A major factor of this difference is that we account only for aircraft at cruising altitudes in the NAFC, whereas, for example, Gettelman and Baughcum [1999] consider global aircraft emissions at all altitudes and flight phases including takeoff, landing and 
Age class 1
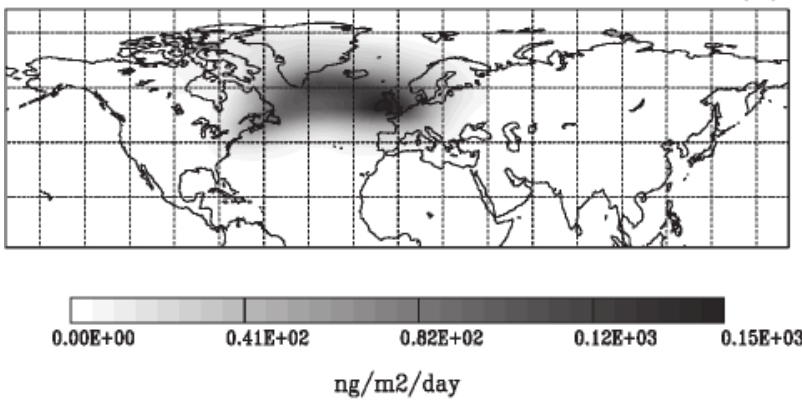

Age class 3
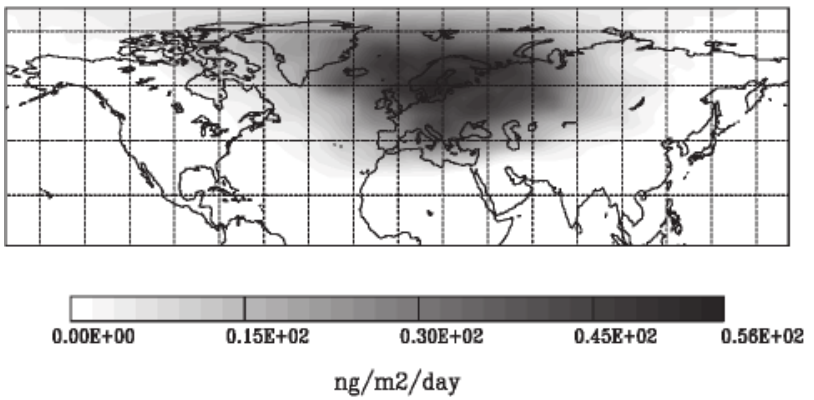

Age class 8

(c)
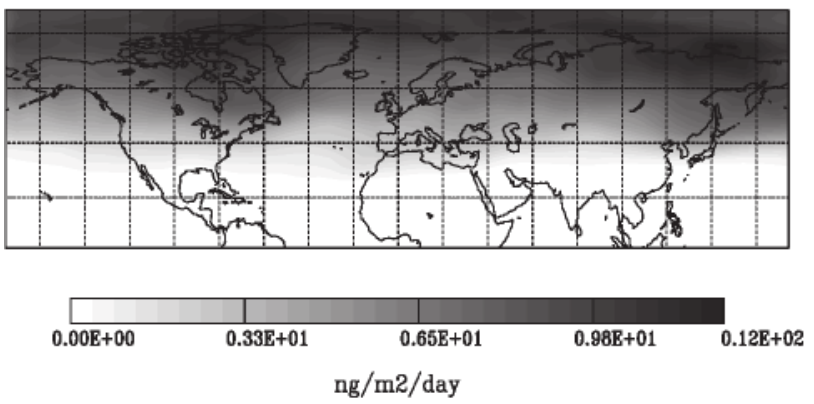

Age class 13

(d)
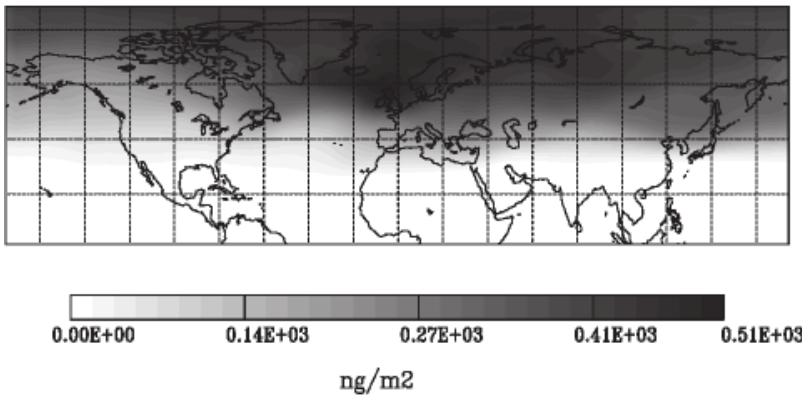

stratosphere to troposphere flux for age class 1

(e)
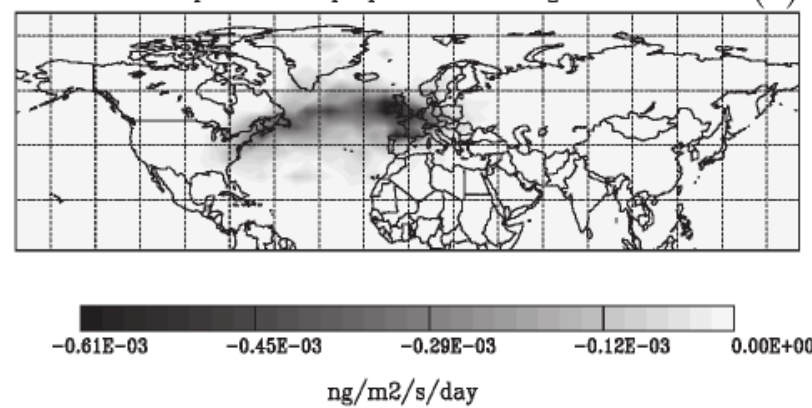

(f)
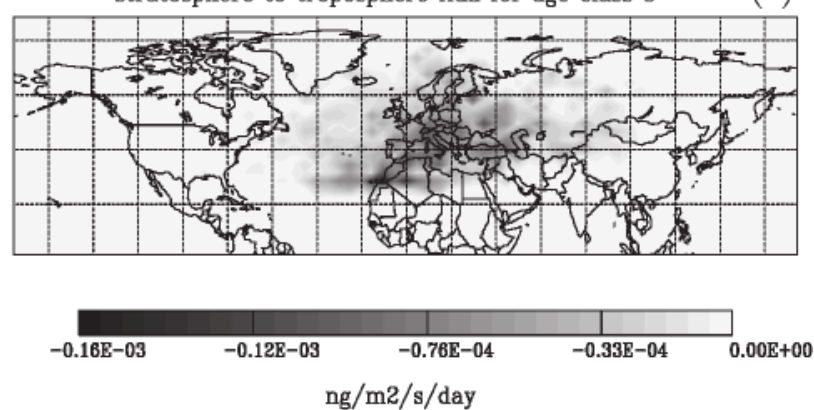

(g)
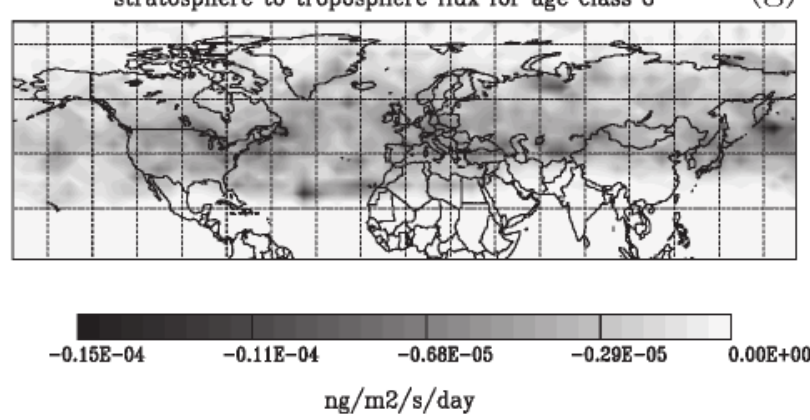

(h)
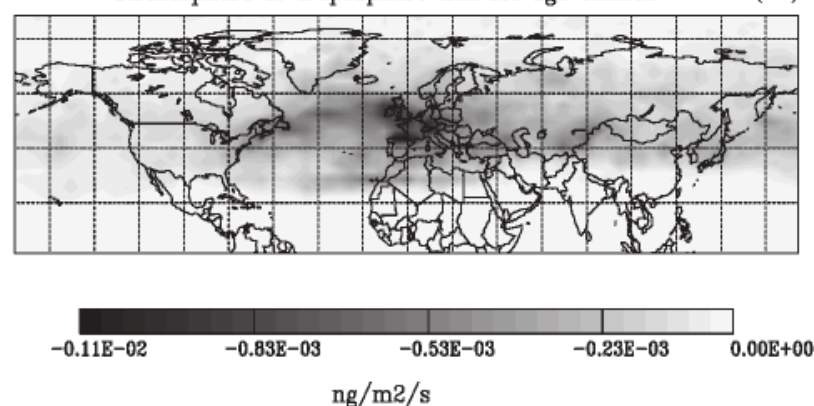

Figure 4. The left row shows the total column of the stratospheric $(\mathrm{P}>2 \mathrm{PVU})$ tracer for the actual run averaged over the period November 1999 to April 2001 for (a) age class 1 (0-1 day), (b) age class 3 (2-3 days), (c) age class $8\left(10-20\right.$ days) in $\mathrm{ng} \mathrm{m}^{-2} \mathrm{~d}^{-1}$, and (d) the sum of all age classes in $\mathrm{ng} \mathrm{m}^{-2}$. The right row displays the corresponding stratosphere to troposphere fluxes for (e) age class 1 (0-1 day), (f) age class 3 (2-3 days), (g) age class 8 (10-20 days) in $\mathrm{kg} \mathrm{m}^{-2} \mathrm{~s}^{-1} \mathrm{~d}^{-1}$, and (h) the sum of all age classes in $\mathrm{kg} \mathrm{m}^{-2}$ s. See color version of this figure at back of this issue. 
short-range flights that do not cruise in the stratosphere or at least fly in the stratosphere for only a short time.

[24] Relative to the actual inventory, $8 \%$ less emissions are released into the stratosphere in the mean inventory. As the MOZAIC flights used in this study were relatively few flights and are not equally distributed over the period regarded here, a substantial part of the differences could arise from the fact that 3\% more MOZAIC flights took place in winter than in summer. It is difficult to say whether the differences between the actual and the mean run would be smaller or greater, if the number of flights was equally distributed over the year or if all air traffic in the NAFC would have been considered. More flights in summer and less in winter could result in a decrease of the stratospheric emissions in the actual inventory, but this decrease depends on the tropopause height and the flight altitudes and could thus be compensated by these factors. Therefore, it can be anticipated that the error due to the deviation from an equal distribution of the flights is small and does not significantly affect our results.

[25] Flight tracks are shifted according to the meteorological situation in order to avoid head winds, take profit from tail winds, and avoid dangerous flight conditions. We find that these adjustments lead to systematically higher emissions in the stratosphere and reduced emissions in the troposphere. However, the increase relative to the mean case is only $8 \%$ of which about half may be due to the fact that more MOZAIC flights took place in winter than in summer. Global chemistry transport models, which use mean inventories, therefore underestimate the emissions into the stratosphere, but by less than $8 \%$. This is a relatively small error and can be tolerated for most applications. However, the ozone budget in the tropopause region is very sensitive to ambient $\mathrm{NO}_{x}$ concentration

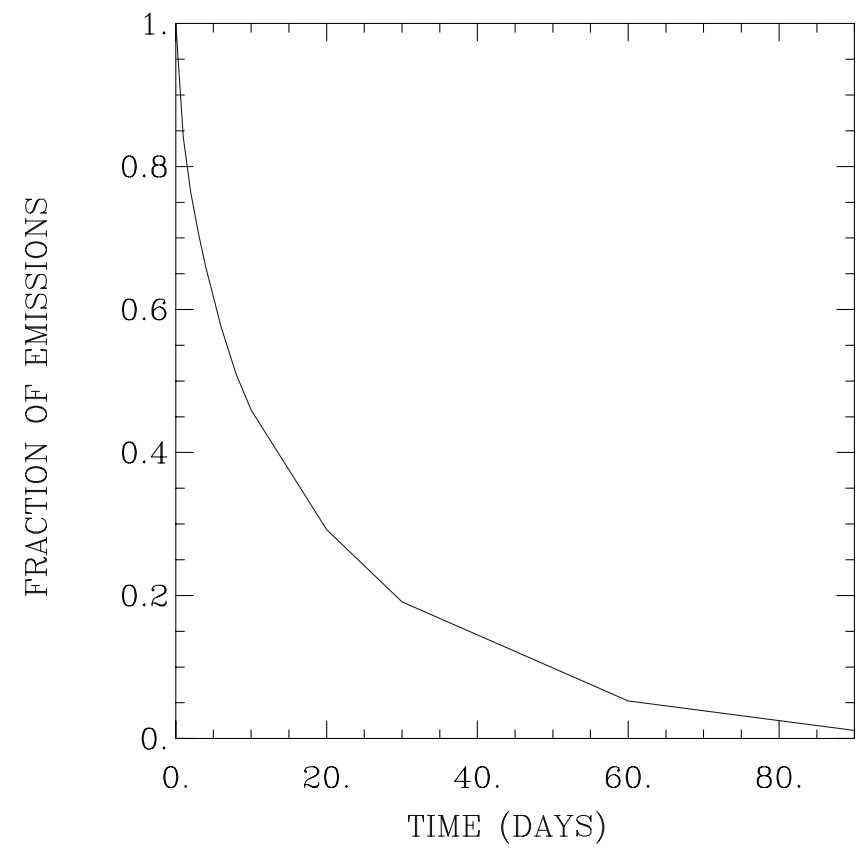

Figure 5. Temporal evolution of the fraction of emissions in the stratosphere relative to the initial emissions deposited in the stratosphere for the actual run.
Difference actual - mean for age class 1

(a)
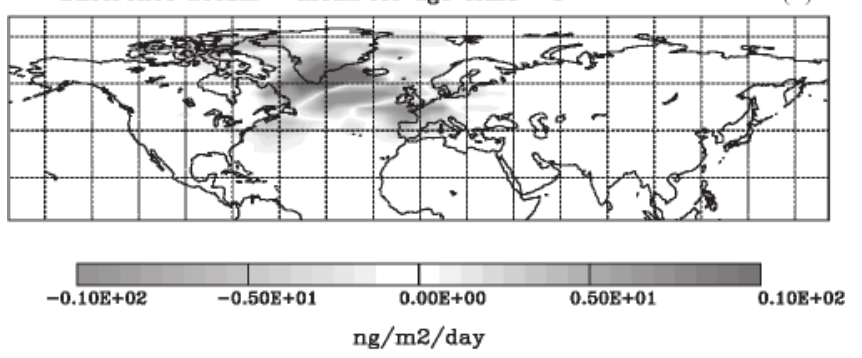

Difference actual - mean for age class 4

(b)
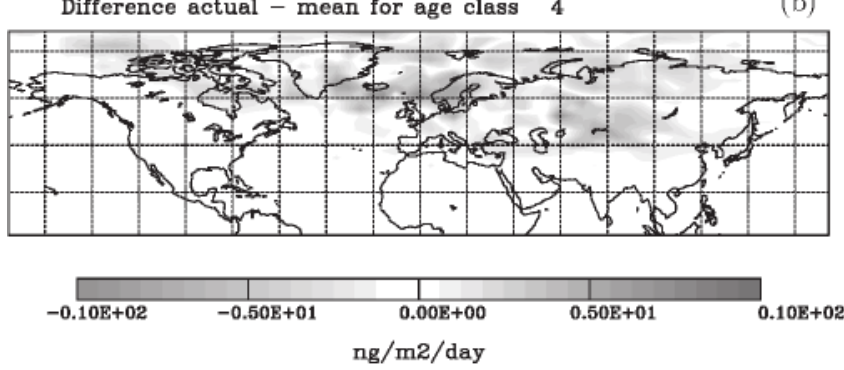

Figure 6. Same as left row in Figure 4 for the actual run minus the mean run for (a) age class 1 ( $0-1$ day) and (b) age class 4 (3-4 days). See color version of this figure at back of this issue.

levels and even relatively small changes in the $\mathrm{NO}_{x}$ concentration can shift the chemistry from net $\mathrm{O}_{3}$ destruction to net $\mathrm{O}_{3}$ formation [IPCC, 1999].

[26] We found a residence time of stratospheric aircraft emissions of about 23 days, which is in agreement with the lifetime found by the Lagrangian study of Schoeberl et al. [1998] for aircraft exhaust released in the lowermost stratosphere. Other studies, however, document considerably longer lifetimes of around 50 days [e.g., Gettelman, 1998]. A reason for this difference is most likely the fact that we consider particles as tropospheric even if they are transported (back) to the stratosphere. This assumption is strict and was not made in previous studies where transport over the tropopause was allowed in both directions [e.g., Gettelman, 1998], i.e., emissions that enter or reenter the stratosphere were taken into account as well, when computing the lifetime. In addition, in chemical transport models the lifetime also depends on the sources and sinks of the considered species in the stratosphere and troposphere. If the boundary layer would be the only $\mathrm{NO}_{x}$ sink and if back transport of initially stratospheric tracer from the free troposphere into the stratosphere would be allowed in our model, we would obtain a lifetime of about 36 days, which is between what we present here and what previous studies with chemical transport models found.

\section{Summary and Conclusions}

[27] In this paper, we investigated the differences in the deposition and the residence time of aircraft emissions in the stratosphere, if emissions along actual flight tracks are used instead of a mean emission inventory. The problem 
was approached by using a Lagrangian dispersion model and MOZAIC aircraft position data over the NAFC during a 1 -year period from November 1999 to October 2000. The MOZAIC data were used to establish two comparable emission inventories, one for emissions along the actual flight tracks and another for mean emissions over the 1-year period. Particles released above the 2 PVU tropopause carried a time flag, which allowed to determine their stratospheric residence times. These residence times were divided into several age classes.

[28] It was found that the stratospheric emissions released in the NAFC are transported in northeasterly directions to polar regions within several days. The maximum fluxes of emissions from the stratosphere to the troposphere take place over Europe and North Africa within the first 10 days. The decline of emissions in the stratosphere can be well described by an exponential decay with an e-folding lifetime of about 23 days. This is shorter than reported in previous studies, because in our study particles are assumed to adopt and keep tropospheric properties as soon as they have entered the troposphere, which was not the case in previous studies [e.g., Gettelman, 1998]. Thus, our estimate of the lifetime might be stricter, and estimates of previous studies should be considered as upper bounds.

[29] In agreement with other studies we found a sensitivity of the deposition of the emissions in the stratosphere for different tropopause definitions. The shift of the flight tracks according to the actual meteorological situation, however, has only a small impact on the partitioning of the emissions relative to the tropopause. In the mean run and in the actual run $62 \%$ and $67 \%$ of the emissions are deposited in the stratosphere, respectively. Therefore, if mean emission inventories are used for climate modelling, the partitioning of emissions in the stratosphere and troposphere can be considered as relatively accurate for most applications as long as the tropopause height is evaluated carefully. However, since in mean inventories emissions into the stratosphere are slightly underestimated, chemistry climate models may underestimate lower stratospheric $\mathrm{NO}_{x}$ levels resulting in errors concerning the photochemical $\mathrm{O}_{3}$ formation.

[30] Acknowledgments. We thank two anonymous reviewers for their insightful comments and suggestions, which helped to improve the presentation of our results. This study was funded by the European Commission as part of the EU project STACCATO (EVK2-CT-199900050).

\section{References}

Anderson, A. D., Subsonic jet aircraft and stratospheric pollution, Water Air Soil Pollut., 2, 427-438, 1973.

Appenzeller, C., H. C. Davies, and W. A. Norton, Fragmentation of stratospheric intrusions, J. Geophys. Res., 101, 1435-1456, 1996.

Baughcum, S. L., Aircraft emissions deposited in the stratosphere and within the Arctic polar vortex, NASA Contract Rep. 4714, 1996.

Baughcum, S. L., T. G. Tritz, S. C. Henderson, and D. C. Pickett, Scheduled civil aircraft emission inventories for 1992: Database development and analysis, NASA Contract Rep. 4700, 1996.

Brasseur, G., et al., Atmospheric impact of $\mathrm{NO}_{x}$ emissions by subsonic aircraft: A three dimensional model study, J. Geophys. Res., 101, 1423-1428, 1996.

Brasseur, G., G. T. Amanatidis, and G. Angeletti, European scientific assessment of the atmospheric effects of aircraft emissions, Atmos. Environ., 32, 2327-2422, 1998.

Brunner, D., J. Staehelin, D. Jeker, H. Wernli, and U. Schumann, Nitrogen oxide and ozone in the tropopause region of the Northern Hemisphere:
Measurements from commercial aircraft in 1996/1996 and 1997, J. Geophys. Res., 106, 27,673-27,699, 2001.

Collins, W. J., D. S. Stevenson, C. E. Johnson, and R. G. Derwent, Tropospheric ozone in a global-scale three-dimensional Lagrangian model and its response to $\mathrm{NO}_{x}$ emission controls, J. Atmos. Chem., 26, 223-274, 1997.

ECMWF, User Guide to ECMWF Products 2.1, Meteorol. Bull., vol. M3.2, ECMWF, Reading, UK, 1995.

Fabian, P., and B. Kärcher, The impact of aviation upon the atmosphere, Phys. Chem. Earth, 22, 503-598, 1997.

Flatøy, F., and Ø. Hov, Three-dimensional model studies of the effect of $\mathrm{NO}_{x}$ emissions from aircraft on ozone in the upper troposphere over Europe and the North Atlantic, J. Geophys. Res., 101, 1001-1422, 1996.

Forster, C., et al., Transport of boreal forest fire emissions from Canada to Europe, J. Geophys. Res., 106, 22,887-22,906, 2001.

Gardner, R. M., et al., The ANCAT/EC global inventory of $\mathrm{NO}_{x}$ emissions from aircraft, Atmos. Environ., 31, 1751-1766, 1997.

Gettelman, A., The evolution of aircraft emissions in the stratosphere, Geophys. Res. Lett., 25, 2129-2132, 1998.

Gettelman, A., and S. L. Baughcum, Direct deposition of subsonic aircraft emissions into the stratosphere, J. Geophys. Res., 104, 8317-8372, 1999.

Hoinka, K. P., Statistics of the global tropopause pressure, Mon. Weather Rev., 126, 3303-3325, 1998.

Hoinka, K. P., M. E. Reinahardt, and W. Metz, North Atlantic airtraffic within the lower stratosphere: Cruising times and corresponding emissions, J. Geophys. Res., 98, 23,113-23,131, 1993.

Holton, J. R., P. H. Haynes, M. E. McIntyre, A. R. Douglas, R. B. Rood, and L. Pfister, Stratosphere-troposphere exchange, Rev. Geophys., 33, 403-439, 1995

IPCC, Aviation and the global atmosphere, in Intergovernmental Panel on Climate Change, edited by J. E. Penner et al., pp. 373, Cambridge Univ. Press, New York, 1999.

Lee, D. S., I. Köhler, E. Grobler, F. Rohrer, R. Sausen, L. Gallardo-Klenner, J. J. G. Olivier, and F. D. Dentener, Estimations of global $\mathrm{NO}_{x}$ emissions and their uncertainties, Atmos. Environ., 31, 1735-1749, 1997.

Logan, J. A., Nitrogen oxides in the troposphere: Global and regional budgets, J. Geophys. Res., 88, 10,785-10,807, 1983.

Marenco, A., et al., Measurement of ozone and water vapour by Airbus inservice aircraft: The MOZAIC airborne program, An overview, J. Geophys. Res., 103, 25,631-25,642, 1998

Reichler, Th., M. Dameris, R. Sausen, and D. Nodorp, A global climatology of the tropopause height based on ECMWF-analyses, Rep. 57, Inst. für Phys. der Atmos., 1996.

Reiter, E. R., M. E. Glasser, and J. D. Mahlmann, The role of the tropopause in stratospheric-tropospheric exchange processes, Pure Appl. Geophys., 75, 185-218, 1969.

Rhode, H., Modeling biochemical cycles, in Global Biochemical Cycles, edited by S. S. Butcher et al., pp. 55-72, Academic, San Diego, Calif., 1992.

Schoeberl, M. R., and G. A. Morris, A Lagrangian simulation of supersonic and subsonic aircraft exhaust emissions, J. Geophys. Res., 105, 11,83311,839, 2000.

Schoeberl, M. R., C. H. Jackman, and J. E. Rosenfeld, A Lagrangian estimate of aircraft effluent lifetime, J. Geophys. Res., 103, 10,817$10,825,1998$.

Schumann, U., On the effect of emissions from aircraft engines on the state of the atmosphere, Ann. Geophys., 12, 365-384, 1994.

Schumann, U., (Ed.), AERONOX: The impact of $\mathrm{NO}_{x}$ emissions from aircraft upon the atmosphere at flight altitudes $8-15 \mathrm{~km}$, Publ. EUR 16209 EN, ISBN-92-826-8281-1, p. 471, Off. for Publ. of the Eur. Comm., Brussels, 1995.

Schumann, U., (Ed.), Pollution from aircraft emissions in the North Atlantic flight corridor (POLINAT 2), Air Pollut. Res. Rep. 58, Rep. EUR 16978 EN, p. 303, Off. for Off. Publ. of the Eur. Communities, Luxembourg, 1997.

Schumann, U., (Ed.), Pollution from aircraft emissions in the North Atlantic flight corridor (POLINAT 2), Air Pollut. Res. Rep. 68, Rep. EUR 18877 EN, p. 312, Off. for Off. Publ. of the Eur. Communities, Luxembourg, 1999.

Singh, H. B., A. M. Thompson, and H. Schlager, SONEX airborne mission and coordinated POLINAT-2 activity: Overview and accomplishments, Geophys. Res. Lett., 26, 3053-3056, 1999.

Stohl, A., and D. J. Thomson, A density correction for Lagrangian particle dispersion models, Boundary Layer Meteorol., 90, 155-167, 1999.

Stohl, A., and T. Trickl, A textbook example of long-range transport: Simultaneous observation of ozone maxima of stratospheric and North American origin in the free troposphere over Europe, J. Geophys. Res., 104, 30,445-30,462, 1999. 
Stohl, A., M. Hittenberger, and G. Wotawa, Validation of the Lagrangian particle dispersion model FLEXPART against large scale tracer experiment data, Atmos. Environ., 24, 4245-4264, 1998.

Thouret, V., B. Sauvage, R. Zbinden, J. P. Cammas, G. Athier, P. Nedelec, and P. Simon, New ozone climatology at $9-12 \mathrm{~km}$ altitude as seen by the MOZAIC program referred to the tropopause altitude, in press, 2002.

Wang, Y., J. A. Logan, and D. J. Jacob, Global simulation of tropospheric $\mathrm{O}_{3}-\mathrm{NO}_{\mathrm{x}}$-hydrocarbon chemistry, 2, Model evaluation and global ozone budget, J. Geophys. Res., 103, 10,727-10,755, 1998.

Wauben, W. M. F., P. F. J. van Velthoven, and H. Kelder, A 3D chemistry transport model study of changes in atmospheric ozone due to aircraft $\mathrm{NO}_{x}$ emissions, Atmos. Environ., 31, 1819-1836, 1997.
World Meteorological Organisation (WMO), Meteorology: A three dimensional science, WMO Bull., 6, 134-138, 1957.

C. Forster, P. James, and A. Stohl, Lehrstuhl für Bioklimatologie und Immissionsforschung, Technische Universität München, Am Hochanger 13, D-85354 Freising-Weihenstephan, Germany. (forster@forst.tu-muenchen. de)

V. Thouret, Laboratoire d'Aérologie, UMR 5560, Centre National de Recherche Scientifique/Université Paul Sabatier, 14 Avenue Edouard Belin, F-31400 Toulouse, France. (thov@aero.obs-mip.fr) 

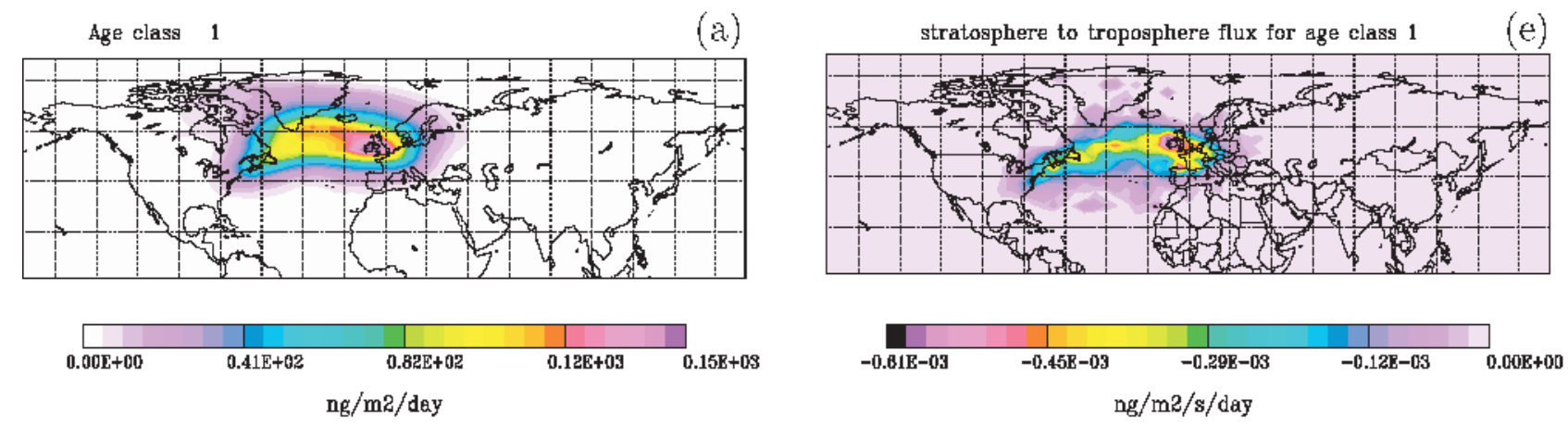

Age class 3
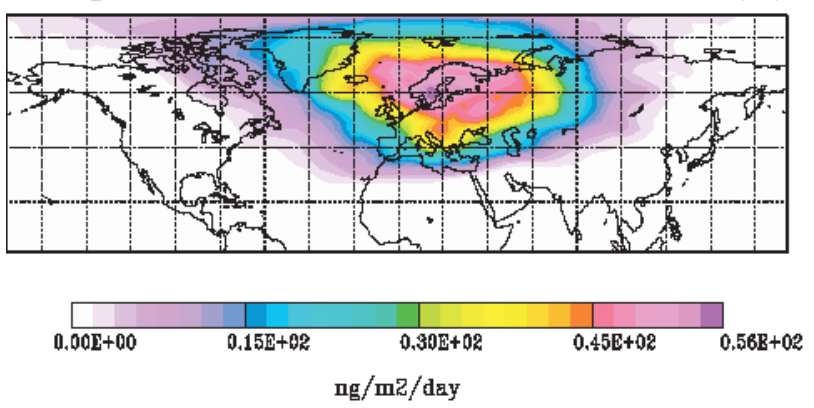

(c)
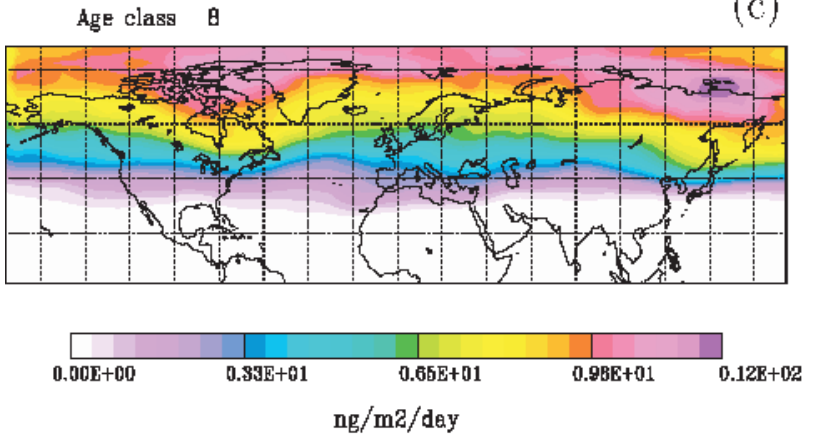

Age class 13

(d)
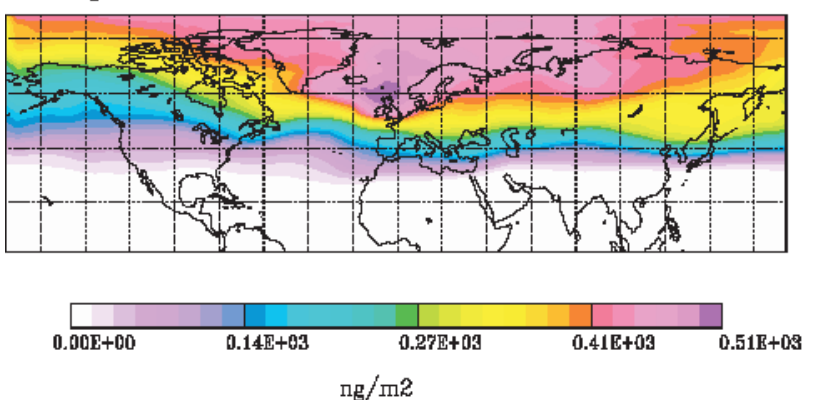

stratosphere to troposphere flux for age class 3

(l)
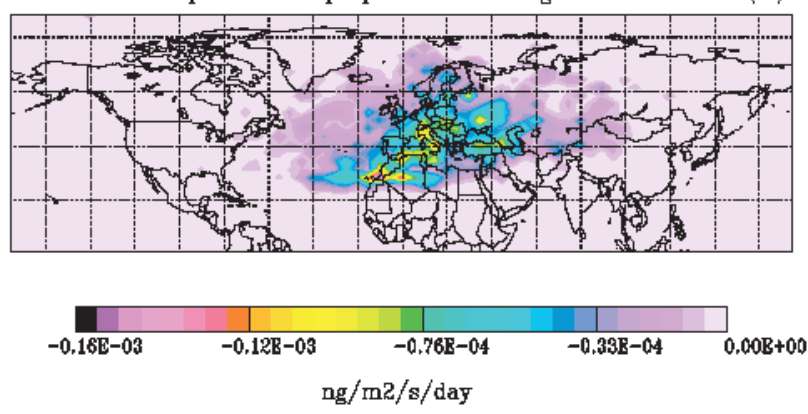

$(\mathrm{g})$
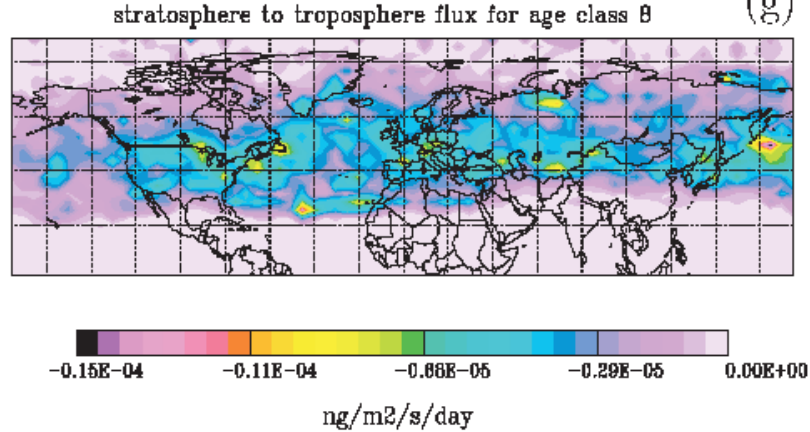

(h)
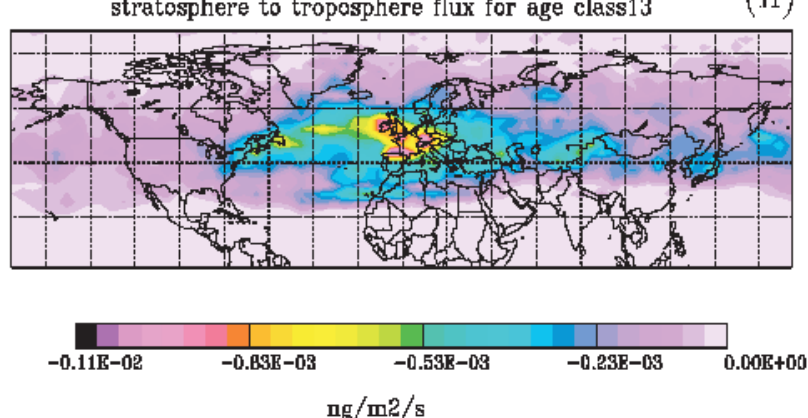

Figure 4. The left row shows the total column of the stratospheric $(\mathrm{P}>2 \mathrm{PVU})$ tracer for the actual run averaged over the period November 1999 to April 2001 for (a) age class 1 (0-1 day), (b) age class 3 (2-3 days), (c) age class $8\left(10-20\right.$ days) in $\mathrm{ng} \mathrm{m}^{-2} \mathrm{~d}^{-1}$, and (d) the sum of all age classes in $\mathrm{ng} \mathrm{m}^{-2}$. The right row displays the corresponding stratosphere to troposphere fluxes for (e) age class 1 (0-1 day), (f) age class 3 (2-3 days), (g) age class $8\left(10-20\right.$ days) in $\mathrm{kg} \mathrm{m}^{-2} \mathrm{~s}^{-1} \mathrm{~d}^{-1}$, and (h) the sum of all age classes in $\mathrm{kg} \mathrm{m}^{-2} \mathrm{~s}$. 


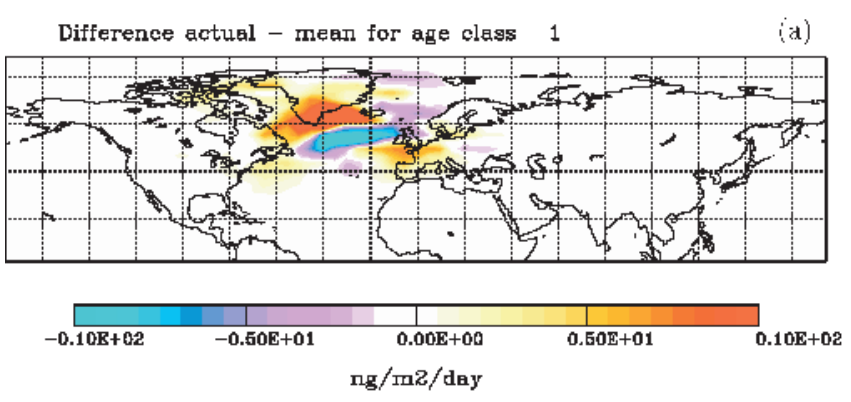

Difference actual - mean for age class 4

(b)

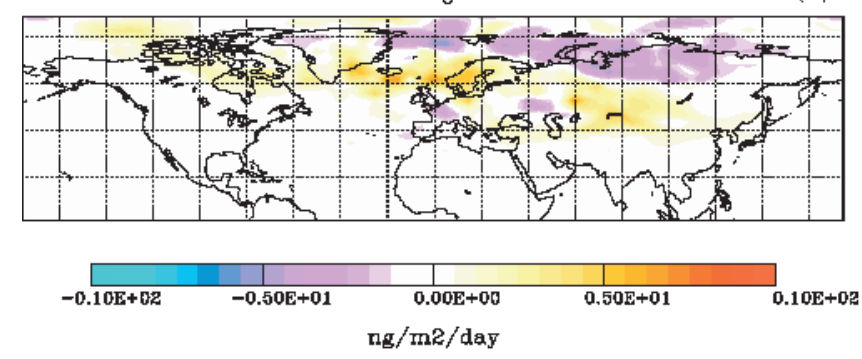

Figure 6. Same as left row in Figure 4 for the actual run minus the mean run for (a) age class $1(0-1$ day) and (b) age class 4 (3-4 days). 